

MEDRESEARCH

www.medresearch.in

\section{International Journal of Medical Research and Review}

2019 Volume 7 Number 6 November-December

\title{
Prevalence of cardiac dysfunction in type 2 diabetes in a tertiary health care setup
}

\author{
Bhavani Prasad N. ${ }^{1}$, Kiran Narukurthi R.. ${ }^{2 *}$, Bhaskar D. ${ }^{3}$, Chandra T. \\ DOI: https://doi.org/10.17511/ijmrr.2019.i06.02
}

\footnotetext{
1 Nakkina Bhavani Prasad, Associate Professor, Department of General Medicine, GSL Medical College, Rajahmundry, Andhra Pradesh, India.

2* Ravi Kiran Narukurthi, Associate Professor, Department of General Medicine, GSL Medical College, Rajahmundry, Andhra Pradesh, India.

3 Bhaskar D, Resident, Department of General Medicine, GSL Medical College, Rajahmundry, Andhra Pradesh, India.

4 T Jaya Chandra, Scientist In charge, Central Research laboratory, GSL Medical College, Rajahmundry, Andhra Pradesh, India.
}

Introduction: Diabetes mellitus (DM) may be one factor that specifically influences cardiac diastolic function. The present study was designed to examine cardiac dysfunction in diabetes subjects with non-chronic renal failure (CRF). Materials and methods: Study was approved by Institutional ethics committee, Informed consent from the study subjects. Diagnosis of diabetes was made according to WHO criteria. Plasma glucose concentration, serum lipids (total cholesterol, triglycerides, LDL cholesterol and HDL plasma cholesterol concentrations) were measured as per standard procedures. Glycosylated hemoglobin (HbA1c) was estimated by ion exchange resin method. ECG recording was obtained for every subject to rule out ischemic heart disease. Results: Of the 150 study Type 2 diabetes participants, the male female ratio was 1.1 . The mean HbA1C was $9.112 \pm 1.36 \%$. 2D ECHO findings showed 34\% left ventricular hypertrophy and $51.3 \%$ diastolic dysfunction. Dyslipidemia was identified in $54.7 \%$ and statistically there was no significant association between dyslipidemia and diastolic dysfunction $(P=0.532)$. Conclusion: In this study, diastolic dysfunction dyslipidemia was identified in $51.5 \%$ participants without dyslipedemia. Though, there was no significant difference, this number is to be considered. However, studies should be conducted with big samples size.

Keywords: Diabetes mellitus, Dyslipidemia, Dysfunction

Corresponding Author

Ravi Kiran Narukurthi, Associate Professor,

Department of General Medicine, GSL Medical College, Rajahmundry, Andhra Pradesh, India.

Email: gslcentralresearchlab@gmail.com
How to Cite this Article

To Browse

Prasad NB, Narukurthi RK, Bhaskar D, Chandra TJ. Prevalence of cardiac dysfunction in type 2 diabetes in a tertiary health care setup. Int J Med Res Rev. 2019;7(6):447-451.

Available From

https://ijmrr.medresearch.in/index.php/ijmrr/article/ view/1093

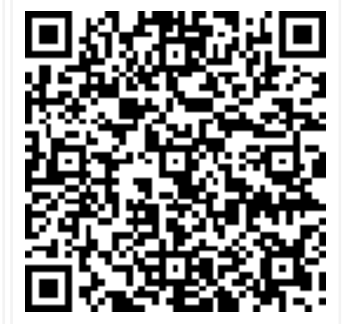

Manuscript Received 2019-10-10

Conflict of Interest No
Review Round 1 2019-10-20

Funding

Nil
Review Round 2

2019-10-25

Ethical Approval

Yes
Review Round 3

Plagiarism X-checker $7 \%$
Accepted 2019-10-31

Note

(C) 2019 by Nakkina Bhavani Prasad, Ravi Kiran Narukurthi, Bhaskar D, T Jaya Chandra and Published by Siddharth Health Research and Social Welfare Society. This is an Open Access article licensed under a Creative Commons Attribution 4.0 International License hittps://creativecommons.org/licenses/by/4.0/ unported [CC BY 4.0]. 


\section{Introduction}

The incidence of diabetes mellitus (DM) is increasing worldwide and rapidly assuming epidemic proportions. India is the diabetes capital with home to 69.1 million people with DM, the second highest number of cases after China [1].

According to International Diabetes Federation estimates, around 415 million people had DM in 2015 and this number is expected to rise to 642 million by 2040 [1]. This global burden of diabetes, brings with it the potential for a catastrophic increase in the prevalence of kidney and cardiovascular disease.

The increased mortality in patients with diabetes traditionally has been attributed to coronary artery disease, more recent studies have emphasized the importance of chronic heart failure (HF) as a common and deadly comorbidity, to which the patient with nephropathy, even in its earliest stages, is especially prone $[2,3]$.

The recognition of such a link between $\mathrm{HF}$ and kidney failure in diabetes is supported not only by epidemiologic data but also by shared pathogenic mechanisms that underlie the development of both disorders and give rise to common therapeutic approaches aimed at slowing their progression [2].Diabetic nephropathy (DN) is the leading cause of end-stage renal disease and the care of patients with diabetes and DN contributes significantly to health care costs. Among these patients with type 1 DM were approximately $20 \%-30 \%$ will eventually develop DN, whereas about $10 \%-20 \%$ of those with type 2 diabetes will do so [4].

Patients with diabetic kidney disease have exceptionally high rates of cardiovascular morbidity and mortality. In fact, the excess mortality among patients with diabetes appears to be largely limited to the subgroup with kidney disease and explained by their high burden of cardiovascular disease. The mechanisms underlying the strong association between diabetic kidney disease and various forms of cardiovascular disease are poorly understood [5].

DM may be one factor that specifically influences cardiac diastolic function, because several studies have shown that diabetes and impaired glucose tolerance selectively accelerate the deterioration of left ventricle (LV) diastolic function. However, little is known about the specific effect of diabetes on LV diastolic function in patients with CRF [6-11].
Due to the limited availability of data on diabetic kidney disease and various forms of cardiovascular disease in this area, the present study was designed to find the association between diastolic function in diabetes subjects with CRF.

\section{Materials and Methods}

Study design: This is a cross sectional study.

Study subjects: All type 2 diabetic subjects who attended the outpatient and inpatient wards of department of general medicine, GSL Medical College who satisfied the inclusion criteria were included in the study.

Study period: 1st November 2015 to 30th April 2017

Sample size: Random sampling was considered during the study period; total 150 patients were included in the study.

Inclusion criteria: All type 2 diabetics above the age of 30 years were included in the study.

Exclusion criteria: Type2 diabetics with ischemic heart disease, hypertension, valvular heart disease, urinary tract infection, poor transthoracic echo window, known renal disease/family history of renal disease were excluded. Study was approved by Institutional ethics committee, Informed consent from the study subjects. A pre-structured questionnaire was used to collect the clinical data. Baseline data including age, detailed medical history, past history, family history, drug history and personal history were recorded. Clinical examination and routine and relevant investigations were carried out for all participants.

Weight of the subjects was measured to the nearest $0.1 \mathrm{~kg}$ in light clothes on standing bare foot using a well calibrated balance scale. Height of the subject was measured to the nearest $0.5 \mathrm{~cm}$ using a wooden scale fixed on the wall on bare foot. BMI was calculated as weight in kilograms divided by height in square meters. Diagnosis of diabetes was made according to WHO criteria or if the subjects were already taking Insulin or oral antidiabetic drugs. Criteria for diagnosis of Diabetes mellitus Subjects with systolic pressure more than $130 \mathrm{~mm}$ $\mathrm{Hg}$ and diastolic pressure more than $90 \mathrm{mmHg}$ or those on antihypertensive drugs were considered as hypertensives. Triglycerides $>150 \mathrm{mg} / \mathrm{dl}$ and $\mathrm{HDL}<40 \mathrm{mg} / \mathrm{dl}$ for males and $<50 \mathrm{mg} / \mathrm{dl}$ for females and on specific treatment was taken as dyslipidemia. 
Venous blood samples were taken after an overnight fast for fasting blood glucose and 2-hour post prandial blood sugar, glycosylated hemoglobin (HbA1c) and lipid profile as per the standard procedures.

ECG recording was obtained for every subject to rule out ischemic heart disease. ECG finding of left ventricular hypertrophy was done by using Sokolowlyon index where the sum of $S$ wave in $V 1$ and $R$ wave in V5 or V6 $35 \mathrm{~mm}, \mathrm{R}$ wave in a VL $>11 \mathrm{~mm}$.

\section{Results}

A total of 150 cases with Type 2 diabetes were included in the study, the male female ratio was 1.1 ; mean age was $56.98 \pm 10.27$ years and ranged between 30 to 88 years. The mean FBS, PPBS were $169.26 \pm 45.282 \mathrm{mg} / \mathrm{dl}$ and $256.69 \pm 71.64 \mathrm{mg} / \mathrm{dl}$, respectively; ranged between 88 to $409 \mathrm{mg} / \mathrm{dl}$ and 152 to $550 \mathrm{mg} / \mathrm{dl}$, respectively. The mean HbA1C was $9.112 \pm 1.36 \%$ with a range between 7.0 to $12.8 \%$.

2D ECHO findings showed $34 \%$ left ventricular hypertrophy and $51.3 \%$ diastolic dysfunction. Dyslipidemia was identified in $54.7 \%$ study population and statistically there was no significant association between dyslipidemia and diastolic dysfunction (Table $1 ; \mathrm{P}=0.532$ )

Tabl-1: Association between dyslipidemia and diastolic dysfunction in study population

\begin{tabular}{|l|l|l|l|}
\hline \multirow{2}{*}{ Dyslipidemia } & \multicolumn{2}{|c|}{ Diastolic dysfunction } & \multirow{2}{*}{ Total } \\
\cline { 2 - 3 } & Absent & Present & \\
\hline Absent & $33(48.5 \%)$ & $35(51.5 \%)$ & $68(100 \%)$ \\
\hline Present & $44(53.7 \%)$ & $38(46.3 \%)$ & $82(100 \%)$ \\
\hline Total & $77(51.3 \%)$ & $73(48.7 \%)$ & $150(100 \%)$ \\
\hline
\end{tabular}

\section{Discussion}

In $\mathrm{HF}$, the coexistence of type $2 \mathrm{DM}$ mainly aggravates LV diastolic dysfunction by increasing LV stiffness and mass, without impairing global pump function [12-14]. CM Schannwell et al. conducted a study to investigate whether young patients with insulin-dependent DM and normal systolic LV function already show a diastolic LV dysfunction and an increased risk of arrhythmias. Even young patients with DM suffer from a diastolic dysfunction while systolic ventricular function is normal. Therefore, echocardiography with measurements of diastolic functional parameters appears to be a sensitive method for evaluating the manifestation and course of early diabetic cardiomyopathy [15].
Bonito et al. stated that, an impairment of LV diastolic function occurs early in the natural history of type $2 \mathrm{DM}$ and is related to clinical evidence of microangiopathic complications [16]. Even the imaging studies have revealed LV concentric remodeling as an important characteristic of diabetic myocardium; this may be associated with reduced systolic strain and impaired myocardial energetic $[17,18]$. Poanta et al. in their study of 58 subjects found that, cardiac autonomic neuropathy was associated with LV diastolic dysfunction in patients with type $2 \mathrm{DM}$, but without clinical manifestation of the heart disease [19].

Whereas in this report, 34\%, 51.3\% ventricular hypertrophy was reported, respectively in left and right areas. Diastolic dysfunction and cardiac autonomic neuropathy (CAN) are associated in patients with otherwise uncomplicated wellcontrolled type 2 DM [12]. Age, duration of DM, glycemic control, the absence or presence of microvascular complications, Dyslipidemia, hypertension and obesity were considered as important risk factors of CAN $[20,21]$.

In DM patients, diastolic dysfunction (impaired relaxation) plays a vital role in the induction of HF with normal systolic function. With a study population of 544, Takeda et al. reported that ejection fraction $\geq 50 \%$ among patients with DM [22]; in this report, the severity of DM and renal dysfunction were not considered. In this study, the diastolic dysfunction was found in 35 and 38 cases among the patients with and without dyslipedemia, respectively(Table 1 ).

In another report by Soldatos et al., the authors reported that significant proportion of study population with type 2 DM were diagnosed to be diastolic dysfunction [23]. Among the asymptomatic and normotensive patients with type 2 diabetes, in this study, $51.3 \%$ patients were diagnosed to be LV diastolic dysfunction; in this, $61.2 \%$ of patients had diabetic nephropathy.

In a report by Boyer et al., the prevalence of LV diastolic dysfunction persons without symptoms and hypertension but having type 2 diabetes disease was reported to be high; the authors reported that diastolic dysfunction was found in $75 \%$ of the study subjects [24]. In Patil et al. study, Out of the total 127 subjects, $69(54.33 \%)$ from the case group had diastolic dysfunction, and $11 \%$ amongst 100 in the control group population showed the diastolic dysfunction $(P<0.001)$ [12]. 
Exiara et al. reported that the prevalence of LV diastolic dysfunction in normotensive, asymptomatic and well-controlled DM type 2 patients is high and increases with age; a total of $63.2 \%$ patients had diastolic dysfunction in their study compared to this study prevalence of $51.3 \%$ [13]. In the present study mean age of the population with diastolic dysfunction was $58.8 \pm 10.64$ years $(p=0.02)$ and the age shows a significant association with diastolic dysfunction. The mean age was reported to be $51 \pm 9$ years $(P>0.05), 43.8 \pm 13.74$ years $(p=0.056)$, respectively by Patil et al [19], and Nikhil et al [24]. By comparing the present study with other studies it showed that age has a significant association with diastolic dysfunction in patients with Type 2 Diabetes. In this study there was significant correlation between age and diastolic dysfunction $(P=0.02)$. However, this correlation could be solely attributed to age factor or due to additive effect of increase in the duration of diabetes with advancing age could not delineated by the present study as all cases studied were diabetes patients. Bhuyan et al. also reported that age is the important risk factor among DM patients [21]; the mean age was reported to be $53.3 \pm 10.37$ years. Usually in Indian culture, this is the important age range of stress due to the responsibilities.

In the present study group out of 150 Type 2 diabetes mellitus patients, $53 \%$ were males and $47 \%$ were females $(p=0.423)$. Patil et al., reported that $54.93 \%$ male and $46.6 \%$ female diagnosed to be diastolic dysfunction [19] and it was 56\%, 44\% by Suresh et al., report [25]. So far, various studies have shown various degrees of association between gender and diastolic dysfunction. In the present study, out of total subjects $51.3 \%$ had diastolic dysfunction. Among them $47.9 \%$ were females and $54.4 \%$ were males. When calculated for correlation between gender and diastolic dysfunction the obtained value $P=0.423$. Thus, present study does not show a strong association between gender and diastolic dysfunction.

\section{Limitation}

The sample size of the study was small; hence results cannot be applied for general population.

\section{What the study adds to the existing knowledge?}

Diastolic dysfunction was observed among the individuals with or without dyslipedemia;
Though statistically there was no significant difference, this has be considered.

\section{Author's contribution}

Dr. Nakkina Bhavani Prasad: Study design, data analysis, paper writing.

Dr. Ravi Kiran Narukurthi: Study design, paper writing.

Dr. Bhaskar D: Bench work, data analysis

Dr. T Jaya Chandra: Data analysis, paper writing

\section{Reference}

01. International Diabetes Federation. IDF Diabetic Atlas. 7th Edition 2019 Book.

[Crossref]

02. Richard E Gilbert, Kim Connelly, Darren J Kelly, Carol A Pollock, Henry Krum. Heart Failure and Nephropathy- Catastrophic and Interrelated Complications of Diabetes. Clin J Am Soc Nephrol. 2006;1(2)193-208.

doi: $10.2215 / \mathrm{CJN} .00540705$ [Crossref]

03. Krum $H$, Gilbert RE. Demographics and concomitant disorders in heart failure. Lancet. 2003;362(9378)147-158.

doi: $10.1016 / S 0140-6736(03) 13869-X \quad$ [Crossref]

04. Zhenhua He. Diagnosis and treatment of diabetic nephropathy in type 1 and type 2 diabetes patients. J Mol Biomark Diagn. $2016 ; 7 ; 295$.

doi: 10.4172/2155-9929.1000295 [Crossref]

05. Pálsson R, Patel UD. Cardiovascular complications of diabetic kidney disease. Advan Chron Kid Dis. 2014;21(3)273-280.

doi: 10.1053/j.ackd.2014.03.003 [Crossref]

06. Celentano A, Vaccaro O, Tammaro $P$, Galderisi $M$, Crivaro $M$, Oliviero $M$, et al. Early abnormalities of cardiac function in non-insulindependent diabetes mellitus and impaired glucose tolerance. Am J Cardiol. $1995 ; 76(16) 1173-1176$.

doi: $10.1016 / \mathrm{s} 0002-9149(99) 80330-0$ [Crossref] 
07. Miyazato J, Horio T, Takiuchi S, Kamide K, Sasaki O, Nakamura S, Nakahama $\mathrm{H}$, et al. Left ventricular diastolic dysfunction in patients with chronic renal failure- impact of diabetes mellitus. Diabet Med. 2005;22(6)730-736.

doi: $10.1111 /$ j.1464-5491.2005.01500.x [Crossref]

08. Liu JE, Palmieri V, Roman MJ, Bella JN, Fabsitz $\mathrm{R}$, Howard $B V$, et al. The impact of diabetes on left ventricular filling pattern in normotensive and hypertensive adults- the Strong Heart Study. J Am Coll Cardiol. 2001;37(7)1943-1949. doi: 10.1016/s0735-1097(01)01230-x [Crossref]

09. Nagano N, Nagano M, Yo Y, Iiyama K, Higaki J, Mikami $\mathrm{H}$, Ogihara T. Role of glucose intolerance in cardiac diastolic function in essential hypertension. Hyperten. 1994;23(6_pt_2)10021005.

[Crossref]

10. Miyazato J, Horio T, Takishita S, Kawano Y. Fasting plasma glucose is an independent determinant of left ventricular diastolic dysfunction in nondiabetic patients with treated essential hypertension. Hyperten Res. 2002;25(3)403-409.

[Crossref]

11. Sato A, Tarnow L, Parving HH. Prevalence of left ventricular hypertrophy in Type I diabetic patients with diabetic nephropathy. Diabetol. 1999;42(1)76-80.

doi: $10.1007 /$ s001250051116 [Crossref]

12. Maack C, Lehrke M, Backs J, Heinzel FR, Hulot JS5, Marx N, et al. Heart failure and diabetes: metabolic alterations and therapeutic interventions- a state-of-the-art review from the Translational Research Committee of the Heart Failure Association-European Society of Cardiology. Eur Heart J. 2018;39(48)42434254.

doi: 10.1093/eurheartj/ehy596 [Crossref]

13. van Heerebeek L, Hamdani N, Handoko ML, Falcao-Pires I, Musters RJ, Kupreishvili K, et al. Diastolic stiffness of the failing diabetic heartimportance of fibrosis, advanced glycation end products, and myocyte resting tension. Circulat. 2008; 117(1)43-51.

doi: $\quad$ 10.1161/CIRCULATIONAHA. 107.728550

[Crossref]
14. Falcão-Pires I, Hamdani N, Borbély A, Gavina C, Schalkwijk CG, van der Velden J, et al. Diabetes mellitus worsens diastolic left ventricular dysfunction in aortic stenosis through altered myocardial structure and cardiomyocyte stiffness. Circulation. 2011;124(10)1151-9.

doi: $\quad$ 10.1161/CIRCULATIONAHA.111.025270

[Crossref]

15. Schannwell CM, Schneppenheim M, Perings $S$, Plehn G, Strauer BE. Left ventricular diastolic dysfunction as an early manifestation of diabetic cardiomyopathy. Cardiol. 2002;98(1-2)33-39. doi: $10.1159 / 000064682$ [Crossref]

16. Di Bonito P, Cuomo S, Moio N, Sibilio G, Sabatini D, Quattrin S, et al. Diastolic dysfunction in pati ents with non-insulin-dependent diabetes mellit us of short duration. Diabet Med. 1996;13(4) 321-4. doi: 10.1002/(SICI)1096-9136(199604)13:4 $<321$ : :AID-DIA3>3.0.CO;2-7 [Crossref]

17. Levelt E, Mahmod M, Piechnik SK, Ariga R, Francis JM, Rodgers CT, et al. Relationship Between Left Ventricular Structural and Metabolic Remodeling in Type 2 Diabetes. Diab. 2016;65(1)44-52.

doi: $10.2337 / \mathrm{db} 15-0627$ [Crossref]

18. Levelt $E$, Pavlides $M$, Banerjee $R$, Mahmod $M$, Kelly C, Sellwood J, et al. Ectopic and Visceral Fat Deposition in Lean and Obese Patients with Type 2 Diabetes. J Am Coll Cardiol. 2016;68(1)53-63.

doi: $10.1016 /$ j.jacc.2016.03.597 [Crossref]

19. Poantă L, Fodor D, Albu A. Left ventricular function in patients with uncomplicated wellcontrolled diabetes mellitus. Med Ultrason. 2010;12(3)184-187.

[Crossref]

20. Serhiyenko VA, Serhiyenko AA. Cardiac autonomic neuropathy- Risk factors, diagnosis and treatment. World J Diabetes. 2018;9(1)124. doi: 10.4239/wjd.v9.i1.1 [Crossref]

21. Bhuyan AK, Baro A, Sarma D, Choudhury B. A Study of Cardiac Autonomic Neuropathy in Patients with Type 2 Diabetes Mellitus- A Northeast India Experience. Indian J Endocrinol Metab. $2019 ; 23(2) 246-250$.

doi: 10.4103/ijem.IJEM_336_18 [Crossref] 
22. Takeda Y, Sakata Y, Mano T, Ohtani T, Kamimura $D$, Tamaki $S$, et al. Competing risks of heart failure with preserved ejection fraction in diabetic patients. Eur J Heart Fail. 2011;13(6)664-669.

doi: $10.1093 /$ eurjhf/hfr019 [Crossref]

23. Large artery biomechanics and diastolic dysfunctionin patients with Type 2 diabetes. Diabet Med. 2011;28(1)54-60. doi: 10.

1111/j.1464-5491.2010.03146.x [Crossref]
24. Nikhil M Dikshit, Parizad Z Wadia, Deepak K Shukla. Diastolic dysfunction in diabetes mellitus. Nat J Med Res. 2013;3(3)249-252.

[Crossref]

25. Kumar VS, Sreelatha M, Ramesh K, Shekar GC. Study of Left Ventricular Diastolic Dysfunction in Type 2 Diabetes Mellitus Patients. In J Sci Study. 2017;5(4)219-224.

doi: $10.17354 /$ ijss/2017/368 [Crossref] 